\title{
Inhalation Injury in the Burned Patient
}

Guillermo Foncerrada, M.D. ${ }^{1,2}$, Derek M. Culnan, M.D. ${ }^{3}$, Karel D. Capek, M.D. ${ }^{1,2}$, Sagrario González-Trejo, M.D. ${ }^{1,2}$, Janos Cambiaso-Daniel, M.D. ${ }^{1,2}$, Lee C. Woodson, M.D., Ph.D. 2,4, David N. Herndon, M.D., F.A.C.S., M.C.C.M., F.R.C.S ${ }^{1,2}$, Celeste C. Finnerty, Ph.D. ${ }^{1,2}$, and Jong O. Lee, M.D. ${ }^{1,2}$

${ }^{1}$ Department of Surgery, University of Texas Medical Branch, Galveston, Texas, USA

${ }^{2}$ Shriners Hospitals for Children - Galveston, Galveston, Texas, USA

3JMS Burn and Reconstructive Center at Merit Health Central, Jackson, MS, USA

${ }^{4}$ Department of Anesthesiology, University of Texas Medical Branch Galveston, Texas, USA

\section{Abstract}

Inhalation injury causes a heterogeneous cascade of insults that increase morbidity and mortality among the burn population. Despite major advancements in burn care over the last several decades, there remains a significant burden of disease attributable to inhalation injury. For this reason effort has been devoted to find new therapeutic approaches to improve outcomes for patients who sustain inhalation injuries.

The three major injury classes are: supraglottic, subglottic, and systemic. Treatment options between these three subtypes differ based on the pathophysiologic changes that each one elicits.

Currently, no consensus exists for diagnosis or grading of the injury and there are large variations in treatment worldwide, ranging from observation and conservative management to advanced therapies with nebulization of different pharmacologic agents.

The main pathophysiologic change after a subglottic inhalation injury is an increase in the bronchial blood flow. An induced mucosal hyperemia leads to edema, increases mucus secretion and plasma transudation into the airways, disables the mucociliary escalator, and inactivates hypoxic vasocontriction. Collectively, these insults potentiate airway obstruction with casts formed from epithelial debris, fibrin clots, and inspissated mucus. resulting in impaired ventilation. Prompt bronchoscopic diagnosis and multimodal treatment improves outcomes. Despite the lack of globally acceptedstandard treatments, data exist to support the use of bronchoscopy and suctioning to remove debris, nebulized heparin for fibrin casts, nebulized n-acetylcysteine for mucus casts, and bronchodilators.

Systemic effects of inhalation injury occur both indirectly from hypoxia or hypercapnia resulting from loss of pulmonary function and systemic effects of pro-inflammatory cytokines, as well as direct effects from metabolic poisons such as carbon monoxide and cyanide. Both present with non-specific clinical symptoms including cardiovascular collapse. Carbon monoxide intoxication should be treated with oxygen and cyanide with hydroxocobalamin. 
Inhalation injury remains a great challenge for clinicians and an area of opportunity for scientists. Management of this concomitant injury lags behind other aspects of burn care. More clinical research is required to improve the outcome of inhalation injury.

The goal of this review is to comprehensively summarize the diagnoses, treatment options, and current research.

\section{Keywords}

inhalation injury; Burns

\section{Introduction}

A serious clinical entity, inhalation injury augments morbidity and increases the probability of death. There is a lack of a consensus diagnostic criteria and grading of the severity, and there is no standardized treatment that reduces morbidity and mortality in these patients.

In the United States, 486,000 burn patients received medical treatment in $2016 .{ }^{1} 3,275$ died as a result of their injuries. Fire and inhalation casualties are combined in this total; deaths from thermal burns cannot always be distinguished from fatalities resulting from the inhalation of smoke and toxins. The National Burn Repository of the American Burn Association reports up to $10.3 \%$ of the burn patients have concomitant inhalation injury. 2,3 As such, 1 in 10 burn patients surviving to admission will have the inhalation injury with the respective increase in the mortality rate.

Of 40,000 hospital admissions from burn injuries, only 30,000 were at burn centers; ;,3 10,000 patients with burns severe enough to meet hospitalization criteria were treated at non-burn centers. This implies the care received was not specialized, and possibly the treatment was not optimal. When treating inhalation injury, the care should be as specialized and as current as possible.

The pulmonary system has three fundamental functions: ventilation, oxygenation, and expectoration. The duration of smoke exposure, temperature of the inhaled smoke, and composition of the smoke are determinants of injury severity. ${ }^{4}$ Inhalation injury is a composite of multiple insults including: supraglottic thermal injury, subglottic airway and alveolar poisoning, and systemic poisoning from absorbed small molecule toxins. These contaminant insults independently affect each of the pulmonary functions as well as having a direct effect on systemic physiology. Further, anatomic characteristics can predispose patients to inhalation injury. For example, an infant will develop airway obstructions much faster than an adult due to reduced airway diameter. Understanding the contributions of each of these pathologies to the patient's disease is critical to managing inhalation injury. 


\section{Pathophysiology}

\section{Supraglottic}

Thermal injury is usually confined to the supraglottis due to low heat capacity of air and efficient heat dissipation in the upper airway as well as the protective effect of the glottis, which tends to close and prevent heat from reaching the infraglottic area. ${ }^{5,6}$ The edema resulting from injury to the supraglottic structures can obstruct the upper airway just hours following insult. ${ }^{7}$ This upper airway edema and obstruction-compromised ventilation can progress quickly with burn edema during resuscitation?

\section{Subglottic}

With the exception of inhaled steam, injury below the glottis is largely chemically derived arising from the inhalation of irritants and noxious chemicals, such as halogen acids, unsaturated aldehydes, and formaldehyde, inflicting damage through direct injury as well as through neurogenic inflammation. ${ }^{8}$ The materials on fire determine the composition of the smoke and the severity of the inflammatory reactions. These provoke a violent response from the lung parenchyma. The principle subglottic pathophysiologic changes occurring after inhalation injury are: airway mucosal hyperemia, bronchospasm, and cast formation from fibrinous exudation into the airways, mucosal sloughing, inspissated mucus, and loss of surfactant and mucociliary escalator function. ${ }^{7}$

To start, chemical irritants and smoke entering the lungs incite production of neuropeptides that trigger a major inflammatory response characterized by activation of the vagal nerve sensory C-fibers, which contain pro-inflammatory peptides, neurokinins, and calcitonin gene-related peptide. ${ }^{9,10}$ Neural endopeptidase targets neuropeptides and plays an important role in pathophysiologic changes. ${ }^{11}$ This leads to bronchoconstriction and activation of nitric oxide synthase (iNOS) that generates reactive oxygen species and inhibits hypoxic pulmonary vasoconstriction. ${ }^{12-14}$ Increased airway blood flow is the main factor underlying pathologic changes. Dysregulation of hypoxic pulmonary vasoconstriction causes a right-toleft shunting of deoxygenated blood and, thus, systemic hypoxemia. Irritation also results in bronchospasm and impairment of gas exchange in distal airways. ${ }^{7}$ Edema results as a secondary consequence of the activation of the inflammatory cascade. ${ }^{15-18}$ These pathologies lead to small airway obstruction, including alveoli, and compromise ventilation, leading to ventilation/perfusion (V/Q) mismatching, causing intrapulmonary shunting and, ultimately, compromising oxygenation. Hypermetabolism and the systemic inflammatory response are much more intense when inhalation injury is accompanied by cutaneous burn. ${ }^{19}$

Airway mucosal hyperemia begins rapidly after inhalation injury. Following inhalation injury, circulation to the right main bronchus increases up to 20 -fold. ${ }^{20}$ This hyperemia provides some physical narrowing of the airways. More significantly, airway hyperemia promotes edema and airway exudation, which together diminish effective airway space through the formation of fibrin and mucus casts inside the alveoli, compromising oxygenation. Due to augmented bronchial blood flow, microvascular pressure and capillary permeability increase while the plasma protein concentration in the intravascular space decreases. As a result, there is an increase in transvascular fluid flux (lymph flow). ${ }^{21}$ 
The etiology of bronchospasm after inhalation injury is unclear, though it may be due to the release of neuropeptides, which are synthesized in the airway submucosa. The degree of spasm depends on the compounds present in the inhaled smoke as well as individual airway sensitivity to the chemical irritants and toxins. ${ }^{22-25}$ The bronchospasm serves to exacerbate the small airway narrowing initiated by airway mucosal hyperemia. This is intensified by the compromised surfactant function that promotes alveolar collapse and atelectasis.

Narrowed airways are ultimately obstructed by airway casts. Airway casts form from blood clots, mucus, and sloughed pulmonary epithelium unable to be expectorated due to impaired mucociliary escalator function. They adhere to the airway wall, reducing luminal space and compromising ventilation. Casts can also obstruct endotracheal cannula. Casts tend to migrate to lower airways due to gravity, and this, combined with impaired ciliary function, produces hypoventilation of the alveoli and shunting, leading to systemic hypoxia. In an inhalation injury animal model, almost $100 \%$ of the epithelial airway cells were sloughed within 24 hours after the insult. ${ }^{26}$ Additionally, the increase in blood flow to the bronchi and consequently to the bronchial mucus glands stimulates mucus secretion. Excessive mucus in the context of impaired ciliary function to clear it leads to the formation of obstructive airway casts and their deleterious effects. ${ }^{27}$ Airway obstruction is life-threatening, and even the obstruction of some proximal bronchi can cause hypoventilation of an entire pulmonary segment. ${ }^{28}$ Further, the loss of the epithelial integrity in addition to impaired cell function in the airway diminishes bacterial clearance, either through ciliary dysfunction or impaired phagocytosis. These issues raise the risk of acquiring an infection of the airway and lungs. Failure to expectorate casts and secretions following inhalation injury can be dangerous and lethal by compromising ventilation and causing shunting that embarrasses oxygenation. ${ }^{29}$

When casts obstruct areas of the injured lung, tidal volumes redistribute to non-obstructed areas. This injures the non-obstructed, functional lung with volutrauma, barotrauma, Acute Respiratory Distress Syndrome (ARDS), and pneumothorax. ${ }^{30}$ These additional insults to the airway increase its susceptibility to infections and permit migration of inflammatory cells into the airway, obstructing alveoli and increasing capillary permeability. This cycle leads to further plasma leak and pulmonary edema, impairing the ventilation/oxygenation ratio and creating right-to-left shunting. ${ }^{31}$ Additionally, casts originate the chain reaction culminating in an intense and generalized inflammation response capable of affecting every organ. ${ }^{32}$ Insufficient oxygen in the body is an independent factor for the release of several cytokines that have proinflammatory effects. ${ }^{33,34}$ Proinflammatory mediators and reactive oxygen species, which also result from administration of oxygen in excess of $60 \%$ for more than 6 hours, contribute to tissue destruction and organ dysfunction. ${ }^{35-40}$

The small airway obstructions caused by mucosal hyperemia, bronchospasm, epithelial and ciliary loss, and the formation of obstructive casts collectively conspire to compromise ventilation, oxygenation, and expectoration in the subglottic component of inhalation injury.

ARDS-Any discussion of the pathophysiology of subglottic inhalation injury must include ARDS as it is a potentially terminal end point. It typically does not develop until 4-8 days postburn. ARDS is the most severe form of acute lung injury that leads to acute respiratory failure and is commonly followed by multisystem organ failure and death. ${ }^{41}$ Annually, 
nearly 200,000 patients are diagnosed with ARDS in the United States, ${ }^{42}$ with a mortality rate reaching $36 \% .{ }^{43}$ Severe burns associate with hypoxemia and the development of ARDS. Clinical manifestations of ARDS include pulmonary edema, inability to ventilate and eliminate carbon dioxide, and marked and severe arterial hypoxemia. If the patient is conscious and not intubated, tachypnea and dyspnea will be prominent. As per the American-European Consensus Conference, the diagnostic criterion was a $\mathrm{PaO}_{2} / \mathrm{FiO}_{2}$ ratio $\leq$ $200 \mathrm{mmHg} .{ }^{43}$ The newer Berlin definition characterizes ARDS as acute, within one week of a clinical event not explained by cardiac failure, or fluid overload and associated with a positive end-expiratory pressure of $\geq 5 \mathrm{cmH}_{2} 0$. ARDS is categorized as mild with a $\mathrm{PaO}_{2} / F_{1} \mathrm{O}_{2}$ between 200-300, moderate between 100-200, and severe below 100.44-46

Inflammation products (e.g., cytokines and coagulation system products) are theorized to induce the alterations representative of ARDS ${ }^{47}$ The influx of protein-rich edema fluid into air spaces consequent of increased permeability of the alveolar-capillary barrier and endothelial injury distinguishes the acute phase of ARDS. Intriguingly, it was demonstrated that the severity of inhalation injury does not correlate to the elaboration of ARDS in burned patients. ${ }^{48}$ While the pathology of smoke inhalation begins proximally in the airways and decreases in effect deeper into the lung, the damage in ARDS begins distally in the alveoli and diminishes as it proceeds proximally. Smoke inhalation and ARDS are two distinct but related conditions.

\section{Systemic Injury}

The pulmonary damage of an inhalation injury has direct systemic pathophysiology including hypoxemia, hypercapnia, acidosis, and systemic inflammation from the myriad of inflammatory mediators elaborated from the lung. Soluble products of combustion, such as carbon monoxide (CO) and cyanide, serve as direct poisons. $\mathrm{CO}$ preferentially binds $\mathrm{Fe}^{2+}$ in hemoglobin compromising tissue oxygenation. Cyanide prefers binding $\mathrm{Fe}^{3+}$ in the mitochondrial cytochromes compromising oxygen utilization and oxidative phosphorylation. These small molecular toxins result from similar combustion processes, occur coincidentally, and act synergistically.

\section{Diagnosis}

No consensus exists regarding the diagnosis, grading, and prognosis of inhalation injury. ${ }^{49}$ Lack of diagnostic consensus may result from delayed presentation. Full manifestation occurs up to 48 hours after the inhalation insult once the inflammation reaches its peak. Further, the clinical presentation (degree of respiratory failure) may not correspond with the intensity of the exposure. ${ }^{50,51}$ In fact, acute lung injury can develop in patients who sustain large cutaneous burns without inhalation injury due to the intense and severe inflammatory response extensive burns elicit in burn patients. ${ }^{52}$ For instance, patients with a considerable total body surface area (TBSA) burn by scald may develop acute lung injury. ${ }^{53}$ Most patients with inhalation injury who arrive early to the emergency room are conscious with a patent airway, and the initial chest radiograph and arterial blood gases may appear at most only slightly abnormal. ${ }^{54}$ As a result of non-specific or delayed presentations, various diagnostic adjuncts are utilized worldwide. 
Findings of a physical exam that can indicate inhalation injury include: sooty sputum, stridor, wheezing, facial burns, singed nasal hairs, anxiety, cough, stupor, signs of hypoxemia, and dyspnea ${ }^{7,8,30,55-57}$. However, physical findings alone can be misleading and should be used in conjunction with other diagnostic adjuncts. One study reported that while $70 \%$ of inhalation injury patients present with facial burns, $70 \%$ of patients with facial burns do not incur significant pulmonary injury ${ }^{58}$. Useful injury history that ought be obtained at admission includes estimated time of exposure, type of burning material(s), location of injury (e.g., enclosed structure, bonfire), and any changes in mental status. ${ }^{7}$

\section{Supraglottic Injury}

Supraglottic injuries are diagnosed on direct visual examination and are often apparent on physical examination. Indirect laryngoscopy permits visual assessment to the level of the vocal cords and can be a useful, albeit limited, tool should bronchoscopy be unavailable to the clinician. ${ }^{59}$ Notably, ingesting scalding liquids can produce oropharyngeal scald burns. These may lead to the development of edema that can occlude the airway with fatal consequences, clinically resembling an edematous epiglottitis. ${ }^{60}$

\section{Subglottic Injury}

While some clinicians rely on a physical examination and the accident history for diagnosis, these are relatively subjective as compared to bronchoscopy. ${ }^{51} \mathrm{~A}$ diagnostic adjunct for acute inhalation injury since $1975,{ }^{61}$ fiberoptic (flexible) bronchoscopy (FOB) is still not universally available, though it is widely used because it provides an immediate view of the airway and is reliable for making a rapid diagnosis of inhalation injury and grading it. As the gold standard for diagnosis, FOB permits direct visualization of both supraglottic and subglottic structures and allows assessment of airway tissue damage from temperature or noxious chemical gases. ${ }^{62}$ Most importantly, while performing the bronchoscopy, the clinician can decide if the patient requires intubation. ${ }^{63}$ Positive findings of inhalation injury from bronchoscopy include: erythema, edema (which may be seen as a blunting of the carina), mucosal blisters, erosions, hemorrhages, bronchial secretions, and soot deposits (Figure 1). ${ }^{7,8}$ As Hunt and colleagues noted, the airway may appear normal and show no signs of mucosal injury, particularly when bronchoscopy is performed very early after the inhalation incident. ${ }^{61}$ Another factor confounding diagnosis is that extensive cutaneous burns elicit a major inflammatory response. Resultantly, acute lung injury and tracheobronchitis may be seen 48 hours post-burn but are unrelated to inhalation injury. Therefore, the physician should supplement the bronchoscopy with physical examination and history of the mechanism of injury to ascertain if inhalation injury is present. Due to the heat transfer process, greater tissue damage can be expected at proximal sites than at distal ones. $^{64}$

Additional diagnostic techniques have been developed and tested; however, these have not been incorporated into standard care protocols because they are too expensive, not readily available worldwide, or do not provide enough information to justify the cost. Xenon-133 scan is a sensitive tool for the diagnosis of inhalation injury. ${ }^{58}$ This useful adjunct can assess the condition of the terminal airways. Various studies have shown that when used in conjunction with FOB or with FOB and pulmonary function tests, diagnoses of inhalation 
injury were $93 \%$ and $96 \%$ accurate, respectively. ${ }^{55,65}$ However, as useful abnormal findings often cannot be measured for several hours postinjury using this method, the delay required may result in the initiation of treatment too late for optimal management. ${ }^{59}$ Gammagram using nebulized technetium-99 has also been used to confirm the diagnosis of inhalation injury. ${ }^{66}$ While highly sensitive, it is not in wide clinical use due to expense, time to acquire the radionuclide, and other logistic difficulties. ${ }^{67,68}$ Another diagnostic adjunct is the chest $\mathrm{X}$-ray. A chest X-ray taken at admission best serves as a baseline for comparison to subsequent ones. A normal chest X-ray on hospital day 1 does not preclude a diagnosis of inhalation injury as pathophysiologic changes may take hours to become apparent in a radiograph. ${ }^{54}$ However, pulmonary infiltrates may indicate severe inhalation injury and susceptibility to significant morbidities. ${ }^{69}$ Chest tomography (CT) may supplement bronchoscopy as well as to grade injury. This adjunct allows the clinician to assess damage to smaller airways. Such damage cannot be assessed by bronchoscopy, which provides views of only the proximal airway. ${ }^{70}$ This handicap to FOB has been theorized as an explanation for the discrepancy between mortality and bronchoscopic-determined severity of injury. ${ }^{57} \mathrm{In}$ assessing the bronchial-wall thickness at admission, one study found that CT measurement significantly correlates to the number of ventilator and ICU days, and the development of pneumonia. ${ }^{71}$ Various approaches have shown utility of a CT scan, but timing of scans and interpretation of findings remain controversial. ${ }^{70,72}$

\section{Systemic Poisoning}

Systemic injury occurs when the toxic compounds such as $\mathrm{CO}$ or cyanide are inhaled and enter the blood. Due to non-specific clinical symptoms, this condition may be dismissed, leading to negative outcomes, including death. Carbon monoxide intoxication can be quickly measured with a pulse $\mathrm{CO}$-oximeter. A newer diagnostic adjunct, it is not readily available at many centers. Laboratory work can take too long, and delays in transfer as well as supplemental oxygen prophylactically given to patients suspected to have inhalation injury can lower carboxyhemoglobin $(\mathrm{COHb})$ concentrations. As $\mathrm{COHb}$ levels may not correlate to the degree of poisoning, injury history and physical examinations are vital diagnostic tools in the setting of carbon monoxide intoxication. Given the half-life of cyanide and no rapid method by which to detect it in the blood, diagnosis of cyanide poisoning largely rests on findings of lactic acidosis and a carboxyhemoglobin concentration greater than $10 \%$ as well as abnormal hemodynamics and a Glasgow Coma Scale less than $14{ }^{7}$

\section{GRADING SCHEME}

Currently, a multicenter study to determine a grading scheme for inhalation injury based on clinical, bronchoscopic, biochemical, and radiographic findings is underway (ClinicalTrials.gov identifier NCT01194024). As no such study has transpired prior, no consensus exists as to a scoring system. The Abbreviated Injury Score corresponds with an increase in impaired gas exchange and mortality ${ }^{73}$. However, studies have found that the $\mathrm{PaO}_{2} / \mathrm{FiO}_{2}$ ratio a more reliable indicator of inhalation injury severity. Yet, this grading utility is impacted by the ventilator settings, and it may be affected by resuscitation volume. 73,74 At Shriners Hospitals for Children - Galveston, we grade the severity as mild, 
moderate or severe based on bronchoscope findings of erythema, secretion, casts, and epithelial sloughing.

\section{TREATMENT}

\section{Supraglottic}

The primary treatment for a supraglottic inhalation injury compromising the airway is orotracheal or nasotracheal intubation. Most intubations occur prior to arrival at the burn center by personnel inexperienced in the management of burn patients. ${ }^{75}$ Early intubation patients are those who receive supplemental oxygen and present with respiratory distress or hypoxemia or with signs of upper airway compromise, such as mucosal edema, erythema, stridor or hoarseness.

Data conflict over the appropriateness of early intubation in burn patients. Pulmonary function tests have been investigated for their utility in identifying need for intubation, but the results did not match the clinical status of the patient. ${ }^{76}$ In a retrospective study evaluating the efficacy of prehospital intubations, it was shown that of 879 patients, only $11.9 \%$ were extubated within 24 hours of admission once inhalation injury was excluded by FOB. ${ }^{77}$ In a recent large study series, more than $33 \%$ of burn patients were extubated within 1 day of intubation without reintubation following transfer to a burn center. ${ }^{75}$ In a smaller series, $53 \%$ of burn patients were extubated on hospital day 1 and almost $65 \%$ by hospital day $2^{78}$. Given the many and various complications that can arise from intubations (e.g., atelectasis, ventilator-associated pneumonia, lost airway, tracheal injury, death), the risk to the patient may outweigh the reward. ${ }^{79}$ In general, intubation is indicated to improve ventilation or oxygenation, or to maintain a compromised airway (Table 2). The best approach is to keep the airway patent until an experienced practitioner can perform FOB and then determine if the tube should be removed.

Maintaining an ETT on a burned face is a significant challenge and accidental extubation is a concern. However, many solutions have been developed. A large survey of American burn centers reported ETTs secured with linen non-adhesive tape in 59\% of cases, manufactured devices in $48 \%$, and orthodontic in $24 \%{ }^{80}$ Septal ties have been utilized to secure nasal intubations at Shriners Hospitals for Children ${ }^{\circledR}$ - Galveston for 20 years without accidental extubation or septic sinusitis complications. ${ }^{81}$ Tracheotomy delivers a durable airway longterm with increased patient comfort. The survey of American burn centers also reported the average tracheotomy is performed at 2 weeks. Despite a consensus that indications exist for earlier tracheotomies, ${ }^{80}$ Terragni et al. found ventilator and ICU days were reduced but no significant improvement in ventilator-associated pneumonia from early tracheotomy in a study of 600 adult ICU patients. ${ }^{82}$

When possible, the patient should receive humidified oxygen to prevent secretions from thickening. The head of the bed should be elevated 45 degrees to reduce supraglottic edema and minimize the pressure exerted by the intra-abdominal structures when the patient is lying flat, and judicious use of steroids and/or diuretics may be helpful. ${ }^{83}$ 


\section{Subglottic}

Management of subglottic inhalation injuries is directed at the principle pathophysiologies, particularly mucosal hyperemia and edema, bronchospasm, expectoration of mucous and casts, and improving V/Q ratio. Care must be taken to limit further harm such as ventilatorinduced injury through excessive pressure (barotrauma), which may be as severe as a tension pneumothorax and, ultimately, life-threatening.

Management of airway hyperemia is currently in preclinical studies. Reduction of airway blood flow through bronchial artery ligation has demonstrated significant improvements in many variables, including reduction in transvascular fluid flux (lymph flow). ${ }^{19,84-87}$ Studies in animal models of inhalation injury showed that bronchial artery ligation diminishes edema. ${ }^{19,88}$ Occlusion of the bronchial artery reduces chemokine levels. ${ }^{85-87}$ These studies support the use of nebulized agents for treating inhalation injury, especially agents that may reduce edema. While many practitioners endeavor to reduce airway edema by restricting fluid resuscitation, patients with inhalation injury require more intravenous fluid for resuscitation than predicted by resuscitation formulas, ${ }^{89}$ which only consider the percent of cutaneous burn. In a preclinical inhalation injury model, fluid restriction exacerbates pulmonary capillary leak and increases lung lymph formation..$^{90}$ Fluid restriction can lead to hypoperfusion, shock, and death, while fluid overload can result in pulmonary edema, right heart failure, compartment syndromes, shock, and death. ${ }^{91}$ Several burn resuscitation formulas can be used to estimate fluid requirements for 24-48 hours post-burn. The rate of the fluid administration requires titration, which can lead to error and suboptimal outcomes. Resultantly, computerized decision support systems have been developed to assist the burn surgeon in fluid resuscitation management. In burn patients, these systems have yielded satisfactory results, with sufficient fluid being administered to patients during resuscitation. 92,93 Regardless of the fluid resuscitation formula employed, the patient should be resuscitated sufficiently to a selected end point and care taken to avoid fluid overload or underload.

Bronchoalveolar lavage is the washing of lung segments often utilized to diagnose infections but does have therapeutic relevance, particularly whole-lung lavage. ${ }^{94,95}$ Saline is used to flush the contaminant materials from the lung until the fluid runs clear. ${ }^{96}$ In reviewing data from the National Burn Repository, Carr and colleagues determined that burn patients with inhalation injury complicated by pneumonia who underwent at least one bronchoscopic procedure had significantly shorter stays in ICUs and hospitals, reduced hospital costs, and a mortality risk reduced by $18 \%$ as compared to burn patients who did not undergo a bronchoscopic procedure. ${ }^{97}$ Patients with less than $60 \%$ TBSA burn who underwent at least one bronchoscopic procedure had decreased days on mechanical ventilation, leading Carr and coworkers to conclude bronchoscopy may be indicated following inhalation injury. ${ }^{97}$

Concerningly, airway pressure may rise to dangerous levels if high tidal volume ventilation is initiated; the probability of tension pneumothorax is latent in this scenario. ${ }^{98}$

Overdistention of the airway stimulates the release of multiple pro-inflammatory cytokines such as interleukin-8, a powerful neutrophil chemotactic factor. This results in even greater injury to the pulmonary tissue cells by the inducement of iNOS that serves to increase production of reactive oxygen species, which overpower the native defenses of the body. ${ }^{57,99}$ 
Therefore, removal of these obstructive casts by medical intervention is vital. However, casts may be lodged in the alveoli, making it difficult or impossible to extract them using mechanical methods such as bronchoalveolar lavage.

Breaking down airway casts and augmenting expectoration comprise the core of managing subglottic inhalation injury. Nebulized fibrinolytics have been evaluated in preclinical inhalation injury models with promising results. ${ }^{100}$ Fibrin casts are broken down with nebulized heparin. ${ }^{101,102}$ Heparin prevents coagulation of transudated plasma leaking from injured pulmonary capillaries. ${ }^{5,103}$ With sloughed mucosa, mucus portions of casts are fragmented by $\mathrm{n}$-acetylcysteine acting as a mucolytic agent and permitting expectoration. ${ }^{104}$ $\mathrm{N}$-acetylcysteine has been shown safe and efficacious. ${ }^{105}$ This combination, nebulized Nacetylcysteine and heparin with albuterol and pulmonary toileting, is a common protocol to treat inhalation injury. ${ }^{104}$ It serves to mediate the cell injury incited by reactive oxygen species induced by iNOS. ${ }^{57}$ Despite noted methodological issues, a meta-analysis comprising 286 burn patients determined inhaled heparin reduced ventilator days and resulted in more patients alive at day 28 with lower lung injury scores. ${ }^{106}$ In a nonburned population, Kashefi and colleagues found an increase in pneumonia rates and no reduction in mortality or mechanical ventilation days from a nebulized heparin and $\mathrm{N}$-acetylcysteine/ albuterol regimen, highlighting the distinct pathology of inhalation injury. ${ }^{107}$ Conversely, a recently published case-control study of 72 inhalation injured burn patients demonstrated a 7-day course of nebulized heparin with $\mathrm{N}$-acetylcysteine and albuterol increased ventilatorfree days and decreased average ventilator days from 14 to 7 . There was no increase in mortality, pneumonia rates, or bleeding in this study, and nebulized heparin was found safe and effective. ${ }^{104}$ This efficacy is consistent with the clinical experience treating burn patients at Shriners Hospitals for Children - Galveston.

Bronchospasm is treated with nebulized bronchodilators. Nebulized epinephrine has been tested in the preclinical setting with satisfactory results by reducing airway pressure and increasing distensibility through its $\beta 2$-agonist effects, causing bronchodilation in models of inhalation injury with cutaneous burns. ${ }^{108}$ Administration of nebulized albuterol or nebulized epinephrine produces immediate effects, provoking bronchodilation and reducing airway pressure. Bronchodilators are also needed when administering $\mathrm{N}$-acetylcysteine due to its potent respiratory irritant profile.

Injured lungs must clear secretions, damaged mucosa, pathogens, and aspirated material. In the case of compromised mucociliary escalators, transudates of fibrinous material and mucosal slough must be expectorated. Bronchoscopy, mucolytics, suctioning, chest physiotherapy, and specific ventilator modes assist in lung expectoration. ${ }^{109}$ Airway suctioning should be performed when needed. If done incautiously, the patient may become hypoxic and bradycardic due to vagal stimulation. Therefore, pre-oxygenation is advisable prior to suction, and suctioning should be done for up to 10 seconds. Chest physiotherapy, including percussive and coughing techniques, should be performed, along with early mobilization. Postural drainage is recommended and should be done when possible. ${ }^{110}$ Collectively, these techniques prevent the accumulation of secretions, which may cause airway obstruction and atelectasis and potentiate pneumonias. ${ }^{111,112}$ Clearance of secretions 
can be eased by chest percussion and vibration such as high-frequency chest wall oscillation. 113

Burn patients present considerable challenges in mechanical ventilation and ARDS from elevated carbon dioxide production because of the hypermetabolic response, perturbed physiology from inhalation injury, reduced compliance from eschar, and pulmonary edema from resuscitation. Ventilator management is centered on ensuring sufficient oxygenation and ventilation and optimizing expectoration, balanced against avoiding second-hit injuries that can incite ARDS. ARDSnet studies demonstrated that ventilator-associated injuries to lungs can trigger ARDS and appreciably affect morbidity and mortality. While ARDSnet upholds utilizing low tidal volume (LTV), these protocols are ineffectual among burn patients; $33 \%$ failed to meet ventilation and oxygenation goals, increasing to about $67 \%$ with concomitant inhalation injury. ${ }^{80}$ Furthermore, the work required to breathe intensifies progressively at low tidal volumes. ${ }^{114}$ Investigating pulmonary outcomes in 932 burned pediatric patients with inhalation injury over 28 years, Sousse and colleagues concluded that high tidal volume $(15+/-3 \mathrm{ml} / \mathrm{kg})$ corresponds with considerably decreased ventilator days and ARDS, maximum positive end-expiratory pressure, significantly increased maximum peak inspiratory pressure, and increased pneumothorax. They determined that high tidal volumes might disrupt the cascade of events leading to lung injury following inhalation injury. ${ }^{115}$

Both volume and pressure-cycled modes are in common use, though the optimal ventilator mode in inhalation injury remains controversial. The open lung strategies airway pressurerelease ventilation (APRV) and high-frequency percussive ventilation (HFPV) augment impaired oxygenation and buttress expectoration and are becoming the standard modes for more burn centers.

APRV provides unceasing positive airway pressure with a time-cycled pressure-release phase to permit ventilation and expectoration. Keeping pressures elevated in the airways for most of the respiratory cycle, this facilitates improved V/Q ratio, extensive alveolar recruitment permitting an open lung, and very high $\mathrm{MAP}-\mathrm{O}_{2}$ to overpower high A-a gradients. ${ }^{116}$

A time-cycled mode, HFPV delivers subtidal pressure-limited breaths at high frequencies (400-800 beats/min) superimposed on a conventional inspiratory and expiratory pressurecontrolled cycle (10-30 breaths/min). This purportedly mobilizes airway secretions and casts, facilitating improved expectoration and pulmonary toilet, and provides adequate gas exchange at lower airway pressures. First reported in 1989, HFPV has been tested primarily in burned patients with inhalation injury. ${ }^{117}$ In this study, HFPV was used as a salvage therapy in one group of burned patients with inhalation injury and as the primary therapy in another group. Improvements in oxygenation and a lower rate of pneumonia were seen. A subsequent study documented an improvement in mortality in burned patients with inhalation injury treated with HFPV compared to historical controls as well as significant decreases in the work of breathing and lower inspiratory pressures in addition to improvements in oxygenation and the rate of pneumonia. ${ }^{118}$ However, some studies have reported no statistically significant differences between pressure-limited strategies versus 
conventional modes in various outcomes (e.g., mortality, pulmonary complications, inflammatory markers) except in barotrauma and improved oxygenation. ${ }^{119,}{ }^{120}$ In the trial comparing HFPV to an ARDSnet-based conventional strategy, a lower incidence of barotrauma was seen in the HFPV group, improved oxygenation early and less rescue needed. ${ }^{120}$ While the efficacy is debated, these data mostly support HFPV as a useful adjunct in managing burn patients.

\section{Systemic}

Treatment for $\mathrm{CO}$ and cyanide intoxication is urgent since these can cause systemic toxicity and can be rapidly fatal. Intoxication should be suspected and ruled out in all patients with intense smoke exposure. When carboxyhemoglobin levels exceed 10\%, 100\% oxygen should be administered via a tightly-fitting high flow mask or endotracheal tube. ${ }^{121} \mathrm{On}$ $100 \%$ oxygen, the half-life of the carboxyhemoglobin was reduced to $74 \pm 25$ minutes from 4-6 hours. ${ }^{122,123}$ Measurement of carboxyhemoglobin on ABG can quantify CO quickly.

Real-time assessment via pulse CO-oximetry is available but not widely adopted. ${ }^{124}$ Controversy exists regarding the use of hyperbaric oxygen in these patients. ${ }^{125}$ Additionally, hyperbaric chambers are not always available and can be costly. However, in patients whose carboxyhemoglobin levels remain high following administration of oxygen or whose mental status deteriorates, hyperbaric oxygen therapy may be indicated. ${ }^{126}$ A $25 \%$ reduction in the incidence of long-term neurological sequelae was reported in patients receiving hyperbaric oxygen therapy as compared to patients receiving other treatments. ${ }^{127}$ Further, this adjunct has been shown to allay the inflammatory processes provoked by $\mathrm{CO}$ poisoning. ${ }^{126}$ However, this must be balanced against other critical care needs.

Cyanide is often present in smoke, particularly when the combustible is plastic. Hydroxocobalamin, the precursor of vitamin B12, is a safe treatment with few side effects. Sulfur donors such as sodium thiosulfate accentuate the conversion of cyanide to thiocyanate, reducing its toxicity. ${ }^{128}$ However, a Task Force of the European Centre for Ecotoxicology and Toxicology of Chemicals determined hydroxocobalamin to be the preferred adjunct to treat cyanide intoxication from smoke inhalation rather than sodium thiosulfate or sodium nitrite. ${ }^{93}$ Treating cyanide poisoning can be an indirect therapy of carbon monoxide intoxication because of the synergistic toxicities of the molecules, thereby shortening the duration of oxygen administration.

\section{CONCLUSION}

Inhalation injuries increase burn mortality through heterogeneous injuries. Limited number of treatment modalities and the lack of a clear diagnostic criteria or grading system to direct therapeutic modalities stymie medical professionals in assessing and managing inhalation injury. This, in turn, has prevented continued significant improvements in this coincident pathology of thermal injury, explaining the high mortality rates resulting from inhalation injury in burn patients. ${ }^{129}$ Further clinical study is required to address this grave condition to better serve this patient population. 


\section{Acknowledgments}

This work was supported by National Institutes of Health (P50 GM060338, R01 GM056687, R01 GM112936), NIDILRR (90DP0043-02-00), and Shriners Hospitals for Children ${ }^{\circledR}(84080,79141,71008,71000)$. It was also made possible with the support of the Institute for Translational Sciences at the University of Texas Medical Branch, supported in part by a Clinical and Translational Science Award (UL1TR000071) from the National Center for Advancing Translational Science. The work contained herein is the authors' own work and does not necessarily reflect the views of the NIH, Shriners Hospitals for Children ${ }^{\circledR}$, or the University of Texas Medical Branch.

We would also like to thank Genevieve Bitz for her myriad of contributions to this manuscript, to Dr. Kasie Cole for her scientific editing and proof-reading the article.

\section{References}

1. Natinal Hospital Ambulatory Medical Care Survey: 2011 Emergency Department Summary Tables. CDC;

2. Burn Incidence Fact Sheet. American Burn Association;

3. 2016 National Burn Repository. American Burn Association; 2017.

4. Kimura R, Traber LD, Herndon DN, Linares HA, Lubbesmeyer HJ, Traber DL. Increasing duration of smoke exposure induces more severe lung injury in sheep. J Appl Physiol (1985). 1988; 64(3): 1107-1113. [PubMed: 3366733]

5. McCall JE, Cahill TJ. Respiratory care of the burn patient. J Burn Care Rehabil. 2005; 26(3):200206. [PubMed: 15879741]

6. Moritz AR, Henriques FC, McLean R. The Effects of Inhaled Heat on the Air Passages and Lungs: An Experimental Investigation. Am J Pathol. 1945; 21(2):311-331. [PubMed: 19970813]

7. Dries DJ, Endorf FW. Inhalation injury: epidemiology, pathology, treatment strategies. Scandinavian journal of trauma, resuscitation and emergency medicine. 2013; 21:31.

8. Walker PF, Buehner MF, Wood LA, et al. Diagnosis and management of inhalation injury: an updated review. Crit Care. 2015; 19:351. [PubMed: 26507130]

9. Brain SD, Cox HM. Neuropeptides and their receptors: innovative science providing novel therapeutic targets. Br J Pharmacol. 2006; 147(Suppl 1):S202-211. [PubMed: 16402106]

10. Dakhama A, Larsen GL, Gelfand EW. Calcitonin gene-related peptide: role in airway homeostasis. Curr Opin Pharmacol. 2004; 4(3):215-220. [PubMed: 15140411]

11. Jacob S, Deyo DJ, Cox RA, Traber DL, Herndon DN, Hawkins HK. Mechanisms of toxic smoke inhalation and burn injury: role of neutral endopeptidase and vascular leakage in mice. Toxicol Mech Methods. 2009; 19(3):191-196. [PubMed: 19727335]

12. Fontan JJ, Cortright DN, Krause JE, et al. Substance P and neurokinin-1 receptor expression by intrinsic airway neurons in the rat. Am J Physiol Lung Cell Mol Physiol. 2000; 278(2):L344-355. [PubMed: 10666119]

13. Kraneveld AD, Nijkamp FP. Tachykinins and neuro-immune interactions in asthma. Int Immunopharmacol. 2001; 1(9-10):1629-1650. [PubMed: 11562057]

14. Sureshbabu A, Bhandari V. Targeting mitochondrial dysfunction in lung diseases: emphasis on mitophagy. Front Physiol. 2013; 4:384. [PubMed: 24421769]

15. Lange M, Enkhbaatar P, Traber DL, et al. Role of calcitonin gene-related peptide (CGRP) in ovine burn and smoke inhalation injury. J Appl Physiol (1985). 2009; 107(1):176-184. [PubMed: 19407258]

16. Nadel JA. Neutral endopeptidase modulates neurogenic inflammation. Eur Respir J. 1991; 4(6): 745-754. [PubMed: 1889501]

17. Richardson JD, Vasko MR. Cellular mechanisms of neurogenic inflammation. J Pharmacol Exp Ther. 2002; 302(3):839-845. [PubMed: 12183638]

18. Solway J, Leff AR. Sensory neuropeptides and airway function. J Appl Physiol (1985). 1991; 71(6):2077-2087. [PubMed: 1663932]

19. Abdi S, Herndon DN, Traber LD, et al. Lung edema formation following inhalation injury: role of the bronchial blood flow. J Appl Physiol (1985). 1991; 71(2):727-734. [PubMed: 1938747] 
20. Lange M, Hamahata A, Traber DL, et al. Preclinical evaluation of epinephrine nebulization to reduce airway hyperemia and improve oxygenation after smoke inhalation injury. Crit Care Med. 2011; 39(4):718-724. [PubMed: 21263320]

21. Rehberg S, Yamamoto Y, Sousse LE, et al. Antithrombin attenuates vascular leakage via inhibiting neutrophil activation in acute lung injury. Crit Care Med. 2013; 41(12):e439-446. [PubMed: 24107637]

22. Jones J, McMullen MJ, Dougherty J. Toxic smoke inhalation: cyanide poisoning in fire victims. Am J Emerg Med. 1987; 5(4):317-321. [PubMed: 3593498]

23. Lundquist $P$, Rammer L, Sorbo B. The role of hydrogen cyanide and carbon monoxide in fire casualties: a prospective study. Forensic Sci Int. 1989; 43(1):9-14. [PubMed: 2556335]

24. Terrill JB, Montgomery RR, Reinhardt CF. Toxic gases from fires. Science. 1978; 200(4348): 1343-1347. [PubMed: 208143]

25. Vogel SN, Sultan TR, Ten Eyck RP. Cyanide poisoning. Clin Toxicol. 1981; 18(3):367-383. [PubMed: 7016420]

26. Cox RA, Jacob S, Zhu Y, et al. Airway obstruction and bacterial invasion in autopsy tissue of pediatric burn victims. Journal of burn care \& research : official publication of the American Burn Association. 2014; 35(2):148-153. [PubMed: 24503967]

27. Cox RA, Mlcak RP, Chinkes DL, et al. Upper airway mucus deposition in lung tissue of burn trauma victims. Shock. 2008; 29(3):356-361. [PubMed: 17693942]

28. Thomas HM 3rd, Garrett RC. Strength of hypoxic vasoconstriction determines shunt fraction in dogs with atelectasis. J Appl Physiol Respir Environ Exerc Physiol. 1982; 53(1):44-51. [PubMed: 6889592]

29. Nakae H, Tanaka H, Inaba H. Failure to clear casts and secretions following inhalation injury can be dangerous: report of a case. Burns. 2001; 27(2):189-191. [PubMed: 11226661]

30. Pruitt BA Jr, Cioffi WG. Diagnosis and treatment of smoke inhalation. J Intensive Care Med. 1995; 10(3):117-127. [PubMed: 10155177]

31. Cox RA, Burke AS, Jacob S, et al. Activated nuclear factor kappa B and airway inflammation after smoke inhalation and burn injury in sheep. Journal of burn care \& research : official publication of the American Burn Association. 2009; 30(3):489-498. [PubMed: 19349878]

32. Fischer S, Clauss M, Wiesnet M, Renz D, Schaper W, Karliczek GF. Hypoxia induces permeability in brain microvessel endothelial cells via VEGF and NO. Am J Physiol. 1999; 276(4 Pt 1):C812820. [PubMed: 10199811]

33. Madjdpour C, Jewell UR, Kneller S, et al. Decreased alveolar oxygen induces lung inflammation. Am J Physiol Lung Cell Mol Physiol. 2003; 284(2):L360-367. [PubMed: 12388372]

34. Wood JG, Johnson JS, Mattioli LF, Gonzalez NC. Systemic hypoxia increases leukocyte emigration and vascular permeability in conscious rats. J Appl Physiol (1985). 2000; 89(4):15611568. [PubMed: 11007596]

35. Basadre JO, Sugi K, Traber DL, Traber LD, Niehaus GD, Herndon DN. The effect of leukocyte depletion on smoke inhalation injury in sheep. Surgery. 1988; 104(2):208-215. [PubMed: 3400056]

36. Morita N, Shimoda K, Traber MG, et al. Vitamin E attenuates acute lung injury in sheep with burn and smoke inhalation injury. Redox Rep. 2006; 11(2):61-70. [PubMed: 16686996]

37. Nguyen TT, Cox CS Jr, Herndon DN, et al. Effects of manganese superoxide dismutase on lung fluid balance after smoke inhalation. J Appl Physiol (1985). 1995; 78(6):2161-2168. [PubMed: 7665413]

38. Niehaus GD, Kimura R, Traber LD, Herndon DN, Flynn JT, Traber DL. Administration of a synthetic antiprotease reduces smoke-induced lung injury. J Appl Physiol (1985). 1990; 69(2): 694-699. [PubMed: 1699920]

39. Virag L. Poly(ADP-ribosyl)ation in asthma and other lung diseases. Pharmacol Res. 2005; 52(1): 83-92. [PubMed: 15911336]

40. Yamamoto Y, Enkhbaatar P, Sousse LE, et al. Nebulization with gamma-tocopherol ameliorates acute lung injury after burn and smoke inhalation in the ovine model. Shock. 2012; 37(4):408-414. [PubMed: 22266978] 
41. Matthay MA, Ware LB, Zimmerman GA. The acute respiratory distress syndrome. J Clin Invest. 2012; 122(8):2731-2740. [PubMed: 22850883]

42. Rubenfeld GD, Caldwell E, Peabody E, et al. Incidence and outcomes of acute lung injury. The New England journal of medicine. 2005; 353(16):1685-1693. [PubMed: 16236739]

43. Erickson SE, Martin GS, Davis JL, Matthay MA, Eisner MD, Network NNA. Recent trends in acute lung injury mortality: 1996-2005. Crit Care Med. 2009; 37(5):1574-1579. [PubMed: 19325464]

44. Fanelli V, Vlachou A, Ghannadian S, Simonetti U, Slutsky AS, Zhang H. Acute respiratory distress syndrome: new definition, current and future therapeutic options. J Thorac Dis. 2013; 5(3):326334. [PubMed: 23825769]

45. Bordes J, Lacroix G, Esnault P, et al. Comparison of the Berlin definition with the American European consensus definition for acute respiratory distress syndrome in burn patients. Burns. 2014; 40(4):562-567. [PubMed: 24685349]

46. Force ADT, Ranieri VM, Rubenfeld GD, et al. Acute respiratory distress syndrome: the Berlin Definition. JAMA. 2012; 307(23):2526-2533. [PubMed: 22797452]

47. Curley GF, Laffey JG, Zhang H, Slutsky AS. Biotrauma and Ventilator Induced Lung Injury: Clinical implications. Chest. 2016

48. Liffner G, Bak Z, Reske A, Sjoberg F. Inhalation injury assessed by score does not contribute to the development of acute respiratory distress syndrome in burn victims. Burns. 2005; 31(3):263-268. [PubMed: 15774279]

49. Enkhbaatar P, Pruitt BA Jr, Suman O, et al. Pathophysiology, research challenges, and clinical management of smoke inhalation injury. Lancet. 2016; 388(10052):1437-1446. [PubMed: 27707500]

50. Woodson LC. Diagnosis and grading of inhalation injury. Journal of burn care \& research : official publication of the American Burn Association. 2009; 30(1):143-145. [PubMed: 19060739]

51. Woodson, LC., Talon, M., Traber, DL., Herndon, DN. Diagnosis and treatment of inhalation injury. In: Herndon, DN., editor. Total Burn Care. 4. Edinburgh: Saunders Elsevier; 2012. p. 229-237.

52. Steinvall I, Bak Z, Sjoberg F. Acute respiratory distress syndrome is as important as inhalation injury for the development of respiratory dysfunction in major burns. Burns. 2008; 34(4):441-451. [PubMed: 18243566]

53. Zak AL, Harrington DT, Barillo DJ, Lawlor DF, Shirani KZ, Goodwin CW. Acute respiratory failure that complicates the resuscitation of pediatric patients with scald injuries. J Burn Care Rehabil. 1999; 20(5):391-399. [PubMed: 10501327]

54. Wittram C, Kenny JB. The admission chest radiograph after acute inhalation injury and burns. Br J Radiol. 1994; 67(800):751-754. [PubMed: 8087478]

55. Cioffi WG Jr, Rue LW 3rd, et al. Diagnosis and treatment of inhalation injuries. Crit Care Nurs Clin North Am. 1991; 3(2):191-198. [PubMed: 2054126]

56. Demling RH. Smoke inhalation lung injury: an update. Eplasty. 2008; 8:e27. [PubMed: 18552974]

57. Traber, DL., Enkhbaatar, P., Maybauer, DM. The pathophysiology of inhalation injury. In: Herndon, DN., editor. Total Burn Care. 4. Philadelphia: Saunders; 2012. p. 219-228.

58. Moylan JA. Inhalation Injury-A Primary Determinant of Survival Following Major Burns. J Burn Care Rehabil. 1981; 2(2):76-85.

59. Peters WJ. Inhalation injury caused by the products of combustion. Can Med Assoc J. 1981; 125(3):249-252. [PubMed: 7023640]

60. Dye DJ, Milling MA, Emmanuel ER, Craddock KV. Toddlers, teapots, and kettles: beware intraoral scalds. BMJ. 1990; 300(6724):597-598. [PubMed: 2108760]

61. Hunt JL, Agee RN, Pruitt BA Jr. Fiberoptic bronchoscopy in acute inhalation injury. J Trauma. 1975; 15(8):641-649. [PubMed: 1152086]

62. Cancio LC. Airway management and smoke inhalation injury in the burn patient. Clin Plast Surg. 2009; 36(4):555-567. [PubMed: 19793551]

63. Muehlberger T, Kunar D, Munster A, Couch M. Efficacy of fiberoptic laryngoscopy in the diagnosis of inhalation injuries. Arch Otolaryngol Head Neck Surg. 1998; 124(9):1003-1007. [PubMed: 9738810] 
64. Haponik, EF., Munster, AM. Diagnosis, impact, and classification of inhalation injury. In: Haponik, EF., Munster, AM., editors. Respiratory injury: smoke inhalation and burns. New York: McGrawHill Inc; 1990. p. 17-45.

65. Agee RN, Long JM 3rd, Hunt JL, et al. Use of 133xenon in early diagnosis of inhalation injury. J Trauma. 1976; 16(3):218-224. [PubMed: 1255837]

66. Lin WY, Kao CH, Wang SJ. Detection of acute inhalation injury in fire victims by means of technetium-99m DTPA radioaerosol inhalation lung scintigraphy. Eur J Nucl Med. 1997; 24(2): 125-129. [PubMed: 9021108]

67. Shiau YC, Liu FY, Tsai JJ, Wang JJ, Ho ST, Kao A. Usefulness of technetium-99m hexamethylpropylene amine oxime lung scan to detect inhalation lung injury of patients with pulmonary symptoms/signs but negative chest radiograph and pulmonary function test findings after a fire accident--a preliminary report. Ann Nucl Med. 2003; 17(6):435-438. [PubMed: 14575375]

68. Tanizaki S. Assessing inhalation injury in the emergency room. Open Access Emerg Med. 2015; 7:31-37. [PubMed: 27147888]

69. Masanes MJ, Legendre C, Lioret N, Saizy R, Lebeau B. Using bronchoscopy and biopsy to diagnose early inhalation injury. Macroscopic and histologic findings. Chest. 1995; 107(5):13651369. [PubMed: 7750332]

70. Oh JS, Chung KK, Allen A, et al. Admission chest CT complements fiberoptic bronchoscopy in prediction of adverse outcomes in thermally injured patients. Journal of burn care \& research : official publication of the American Burn Association. 2012; 33(4):532-538. [PubMed: 22210063]

71. Yamamura H, Kaga S, Kaneda K, Mizobata Y. Chest computed tomography performed on admission helps predict the severity of smoke-inhalation injury. Crit Care. 2013; 17(3):R95. [PubMed: 23706091]

72. Kwon HP, Zanders TB, Regn DD, et al. Comparison of virtual bronchoscopy to fiber-optic bronchoscopy for assessment of inhalation injury severity. Burns. 2014; 40(7):1308-1315. [PubMed: 25112807]

73. Hassan Z, Wong JK, Bush J, Bayat A, Dunn KW. Assessing the severity of inhalation injuries in adults. Burns. 2010; 36(2):212-216. [PubMed: 20006445]

74. Ryan CM, Fagan SP, Goverman J, Sheridan RL. Grading inhalation injury by admission bronchoscopy. Crit Care Med. 2012; 40(4):1345-1346. [PubMed: 22425833]

75. Romanowski KS, Palmieri TL, Sen S, Greenhalgh DG. More than one third of intubations in patients transferred to burn centers are unnecessary: Proposed guidelines for appropriate intubation of the burn patient. Journal of burn care \& research : official publication of the American Burn Association. 2015; 37(5):e409-414.

76. Haponik EF, Meyers DA, Munster AM, et al. Acute upper airway injury in burn patients. Serial changes of flow-volume curves and nasopharyngoscopy. Am Rev Respir Dis. 1987; 135(2):360 366. [PubMed: 3813197]

77. Eastman AL, Arnoldo BA, Hunt JL, Purdue GF. Pre-burn center management of the burned airway: do we know enough? Journal of burn care \& research : official publication of the American Burn Association. 2010; 31(5):701-705. [PubMed: 20634705]

78. Klein MB, Nathens AB, Emerson D, Heimbach DM, Gibran NS. An analysis of the long-distance transport of burn patients to a regional burn center. Journal of burn care \#x00026; research : official publication of the American Burn Association. 2007; 28(1):49-55.

79. Romanowski KS, Palmieri TL, Sen S, Greenhalgh DG. More Than One Third of Intubations in Patients Transferred to Burn Centers are Unnecessary: Proposed Guidelines for Appropriate Intubation of the Burn Patient. Journal of burn care \& research : official publication of the American Burn Association. 2015

80. Chung KK, Rhie RY, Lundy JB, et al. A Survey of Mechanical Ventilator Practices Across Burn Centers in North America. Journal of burn care \& research : official publication of the American Burn Association. 2016; 37(2):e131-139. [PubMed: 26135527]

81. Culnan, DM., Sherman, WC., Chung, KK., Wolf, SE. Critical Care in the Severely Burned: Unit Organization, Organ Support and Management of Complications. In: Herndon, DN., editor. Total Burn Care. 5. London: Elsevier; 2017. 
82. Terragni PP, Antonelli M, Fumagalli R, et al. Early vs late tracheotomy for prevention of pneumonia in mechanically ventilated adult ICU patients: a randomized controlled trial. JAMA. 2010; 303(15):1483-1489. [PubMed: 20407057]

83. DeMuro JP, Mongelli MN, Hanna AF. Perioperative upper airway edema: Risk factors and management. Crit Care \& Shock. 2013; 16(4):125-132.

84. Efimova O, Volokhov AB, Iliaifar S, Hales CA. Ligation of the bronchial artery in sheep attenuates early pulmonary changes following exposure to smoke. J Appl Physiol (1985). 2000; 88(3):888893. [PubMed: 10710383]

85. Hamahata A, Enkhbaatar P, Sakurai H, Nozaki M, Traber DL. Effect of ablated bronchial blood flow on survival rate and pulmonary function after burn and smoke inhalation in sheep. Burns. 2009; 35(6):802-810. [PubMed: 19303716]

86. Morita N, Enkhbaatar P, Maybauer DM, et al. Impact of bronchial circulation on bronchial exudates following combined burn and smoke inhalation injury in sheep. Burns. 2011; 37(3):465473. [PubMed: 21195551]

87. Sakurai H, Johnigan R, Kikuchi Y, Harada M, Traber LD, Traber DL. Effect of reduced bronchial circulation on lung fluid flux after smoke inhalation in sheep. J Appl Physiol (1985). 1998; 84(3): 980-986. [PubMed: 9480960]

88. Hales CA, Barkin P, Jung W, Quinn D, Lamborghini D, Burke J. Bronchial artery ligation modifies pulmonary edema after exposure to smoke with acrolein. J Appl Physiol (1985). 1989; 67(3): 1001-1006. [PubMed: 2793693]

89. Navar PD, Saffle JR, Warden GD. Effect of inhalation injury on fluid resuscitation requirements after thermal injury. Am J Surg. 1985; 150(6):716-720. [PubMed: 4073365]

90. Herndon DN, Traber DL, Traber LD. The effect of resuscitation on inhalation injury. Surgery. 1986; 100(2):248-251. [PubMed: 3738753]

91. Herndon DN, Barrow RE, Linares HA, et al. Inhalation injury in burned patients: effects and treatment. Burns Incl Therm Inj. 1988; 14(5):349-356. [PubMed: 3228693]

92. Cartotto R, Greenhalgh DG, Cancio C. Burn State of the Science: Fluid Resuscitation. Journal of burn care \& research : official publication of the American Burn Association. 2017; 38(3):e596e604. [PubMed: 28328669]

93. Salinas J, Chung KK, Mann EA, et al. Computerized decision support system improves fluid resuscitation following severe burns: an original study. Crit Care Med. 2011; 39(9):2031-2038. [PubMed: 21532472]

94. Danel C, Israel-Biet D, Costabel U, Klech H. Therapeutic applications of bronchoalveolar lavage. Eur Respir J. 1992; 5(10):1173-1175. [PubMed: 1486961]

95. Vymazal T, Krecmerova M. Respiratory strategies and airway management in patients with pulmonary alveolar proteinosis: a review. Biomed Res Int. 2015; 2015:639543. [PubMed: 26495308]

96. Awab A, Khan MS, Youness HA. Whole lung lavage-technical details, challenges and management of complications. J Thorac Dis. 2017; 9(6):1697-1706. [PubMed: 28740686]

97. Carr JA, Phillips BD, Bowling WM. The utility of bronchoscopy after inhalation injury complicated by pneumonia in burn patients: results from the National Burn Repository. Journal of burn care \& research : official publication of the American Burn Association. 2009; 30(6):967974. [PubMed: 19826269]

98. Dreyfuss D, Martin-Lefevre L, Saumon G. Hyperinflation-induced lung injury during alveolar flooding in rats: effect of perfluorocarbon instillation. Am J Respir Crit Care Med. 1999; 159(6): 1752-1757. [PubMed: 10351914]

99. Yamamoto H, Teramoto H, Uetani K, Igawa K, Shimizu E. Cyclic stretch upregulates interleukin-8 and transforming growth factor-beta1 production through a protein kinase $\mathrm{C}$-dependent pathway in alveolar epithelial cells. Respirology. 2002; 7(2):103-109. [PubMed: 11985731]

100. Enkhbaatar P, Murakami K, Cox R, et al. Aerosolized tissue plasminogen inhibitor improves pulmonary function in sheep with burn and smoke inhalation. Shock. 2004; 22(1):70-75. [PubMed: 15201705] 
101. Enkhbaatar P, Cox RA, Traber LD, et al. Aerosolized anticoagulants ameliorate acute lung injury in sheep after exposure to burn and smoke inhalation. Crit Care Med. 2007; 35(12):2805-2810. [PubMed: 18074480]

102. Enkhbaatar P, Esechie A, Wang J, et al. Combined anticoagulants ameliorate acute lung injury in sheep after burn and smoke inhalation. Clin Sci (Lond). 2008; 114(4):321-329. [PubMed: 17927568]

103. Cox CS Jr, Zwischenberger JB, Traber DL, Traber LD, Haque AK, Herndon DN. Heparin improves oxygenation and minimizes barotrauma after severe smoke inhalation in an ovine model. Surg Gynecol Obstet. 1993; 176(4):339-349. [PubMed: 8460409]

104. McIntire A, Harris SA, Whitten JA, et al. Outcomes Following the Use of Nebulized Heparin for Inhalation Injury (HIHI Study). Journal of burn care \& research : official publication of the American Burn Association. 2016

105. Desai MH, Mlcak R, Richardson J, Nichols R, Herndon DN. Reduction in mortality in pediatric patients with inhalation injury with aerosolized heparin/ $\mathrm{N}$-acetylcystine [correction of acetylcystine] therapy. J Burn Care Rehabil. 1998; 19(3):210-212. [PubMed: 9622463]

106. Glas GJ, Serpa Neto A, Horn J, et al. Nebulized heparin for patients under mechanical ventilation: an individual patient data meta-analysis. Ann Intensive Care. 2016; 6(1):33. [PubMed: 27083915]

107. Kashefi NS, Nathan JI, Dissanaike S. Does a Nebulized Heparin/N-acetylcysteine Protocol Improve Outcomes in Adult Smoke Inhalation? Plast Reconstr Surg Glob Open. 2014; 2(6):e165. [PubMed: 25289358]

108. Lopez E, Fujiwara O, Lima-Lopez F, et al. Nebulized Epinephrine Limits Pulmonary Vascular Hyperpermeability to Water and Protein in Ovine With Burn and Smoke Inhalation Injury. Crit Care Med. 2016; 44(2):e89-96. [PubMed: 26465218]

109. Sheridan RL. Fire-Related Inhalation Injury. The New England journal of medicine. 2016; 375(5): 464-469. [PubMed: 27518664]

110. Silverberg R, Johnson J, Gorga D, Nagler W, Goodwin C. A survey of the prevalence and application of chest physical therapy in U.S. burn centers. J Burn Care Rehabil. 1995; 16(2 Pt 1): 154-159. [PubMed: 7775511]

111. Desai MH, Rutan RL, Herndon DN. Managing smoke inhalation injuries. Postgrad Med. 1989; 86(8):69-70. 73-66. [PubMed: 2587465]

112. Herndon DN, Thompson PB, Traber DL. Pulmonary injury in burned patients. Crit Care Clin. 1985; 1(1):79-96. [PubMed: 3916776]

113. Koga T, Kawazu T, Iwashita K, Yahata R. Pulmonary hyperinflation and respiratory distress following solvent aspiration in a patient with asthma: expectoration of bronchial casts and clinical improvement with high-frequency chest wall oscillation. Respir Care. 2004; 49(11): 1335-1338. [PubMed: 15507168]

114. Kallet RH, Campbell AR, Dicker RA, Katz JA, Mackersie RC. Effects of tidal volume on work of breathing during lung-protective ventilation in patients with acute lung injury and acute respiratory distress syndrome. Crit Care Med. 2006; 34(1):8-14. [PubMed: 16374150]

115. Sousse LE, Herndon DN, Andersen CR, et al. High tidal volume decreases adult respiratory distress syndrome, atelectasis, and ventilator days compared with low tidal volume in pediatric burned patients with inhalation injury. J Am Coll Surg. 2015; 220(4):570-578. [PubMed: 25724604]

116. Maxwell RA, Green JM, Waldrop J, et al. A randomized prospective trial of airway pressure release ventilation and low tidal volume ventilation in adult trauma patients with acute respiratory failure. J Trauma. 2010; 69(3):501-510. discussion 511. [PubMed: 20838119]

117. Cioffi WG, Graves TA, McManus WF, Pruitt BA Jr. High-frequency percussive ventilation in patients with inhalation injury. J Trauma. 1989; 29(3):350-354. [PubMed: 2926848]

118. Cortiella J, Mlcak R, Herndon D. High frequency percussive ventilation in pediatric patients with inhalation injury. J Burn Care Rehabil. 1999; 20(3):232-235. [PubMed: 10342478]

119. Wolter TP, Fuchs PC, Horvat N, Pallua N. Is high PEEP low volume ventilation in burn patients beneficial? A retrospective study of 61 patients. Burns. 2004; 30(4):368-373. [PubMed: 15145196] 
120. Chung KK, Wolf SE, Renz EM, et al. High-frequency percussive ventilation and low tidal volume ventilation in burns: a randomized controlled trial. Crit Care Med. 2010; 38(10):1970-1977. [PubMed: 20639746]

121. Weaver LK. Clinical practice. Carbon monoxide poisoning. The New England journal of medicine. 2009; 360(12):1217-1225. [PubMed: 19297574]

122. Weaver LK, Howe S, Hopkins R, Chan KJ. Carboxyhemoglobin half-life in carbon monoxidepoisoned patients treated with $100 \%$ oxygen at atmospheric pressure. Chest. 2000; 117(3):801808. [PubMed: 10713010]

123. Bleecker ML. Carbon monoxide intoxication. Handb Clin Neurol. 2015; 131:191-203. [PubMed: 26563790]

124. Piatkowski A, Ulrich D, Grieb G, Pallua N. A new tool for the early diagnosis of carbon monoxide intoxication. Inhal Toxicol. 2009; 21(13):1144-1147. [PubMed: 19852557]

125. Kealey GP. Carbon monoxide toxicity. Journal of burn care \& research : official publication of the American Burn Association. 2009; 30(1):146-147. [PubMed: 19060737]

126. Weaver LK. Hyperbaric oxygen therapy for carbon monoxide poisoning. Undersea Hyperb Med. 2014; 41(4):339-354. [PubMed: 25109087]

127. Weaver LK, Hopkins RO, Chan KJ, et al. Hyperbaric oxygen for acute carbon monoxide poisoning. The New England journal of medicine. 2002; 347(14):1057-1067. [PubMed: 12362006]

128. Hardman, JG.Limbird, LE., Gilman, AG., editors. Goodman \& Gilman's The Pharmacological Basis of Therapeutics. 10. New York: McGraw-Hill; 2001.

129. Toon MH, Maybauer MO, Greenwood JE, Maybauer DM, Fraser JF. Management of acute smoke inhalation injury. Crit Care Resusc. 2010; 12(1):53-61. [PubMed: 20196715] 

ID. No. :
Name :

Sex: Age:

D. 0. Birth:

$02 / 15 / 2006$

$15: 06: 43$

CVP:

D. F :

EH: 1 G : N

Physician:

Comment :

Figure 1.

Bronchoscopic image of trachea in inhalation injury. 


\section{Table 1}

Evidence-based treatment protocol for patients with smoke inhalation injury at Shriners Hospitals for Children ${ }^{\circledR}$ at Galveston

\footnotetext{
- $\quad$ Nebulize $20 \%$ N-acetylcysteine $(3 \mathrm{~mL}$ ) every 4 hours for 7 days;

- Alternate aerosolizing 10,000 units of heparin (in $3 \mathrm{~mL}$ normal saline) every 4 hours for 7 days

- $\quad$ Nebulize with albuterol in case of wheezing
} 


\section{Table 2}

Guidelines for intubation in the pre-burn center setting. Courtesy of Romanowski KS, Palmieri TL, Sen S, Greenhalgh DG. More than one third of intubations in patients transferred to burn centers are unnecessary: Proposed guidelines for appropriate intubation of the burn patient. J Burn Care Res. 2015;37(5):e409-14.

Guidelines for intubation in the pre-burn center setting

- Patient safety should not be compromised, and patient status is the ultimate determinant of intubation need

- Standard indications for intubation should be followed, including but not limited to shortness of breath, wheezing, stridor, hoarseness, combativeness, or decreased level of consciousness

- Contact should be made with the regional burn center as soon as is safely feasible to discuss the events surrounding the burn and need for intubation

- If the patient is clinically stable with no signs or symptoms of compromised airway, burns with lower need for intubation before transfer to a burn center are as follows:

○ Burns that occur from causes other than flame injury

- Burns that do not occur in enclosed spaces

- Burns that are less than $20 \%$ total body surface area

- Burns that have no third degree burns to the face

○ Patient is within a reasonable distance to a burn center (approximately 3-hour transfer time) 